\section{Isolation of Cronobacter spp. (Enterobacter sakazakii) from artisanal mozzarella}

\author{
Francesco Casalinuovo, ${ }^{1}$ Paola Rippa, ${ }^{1}$ \\ Luciana Battaglia, ${ }^{2}$ Nicola Parisi ${ }^{2}$ \\ 'Istituto Zooprofilattico Sperimentale del \\ Mezzogiorno - Sezione di Catanzaro; \\ ${ }^{2}$ Azienda Sanitaria Provinciale \\ di Catanzaro, Italy
}

\section{Abstract}

Cronobacter spp. (Enterobacter sakazakii) is an opportunistic bacterial pathogen capable of causing disease and even fatalities in newborn infants within the first weeks of life if consumed as part of the diet. Premature and immunocompromised newborn infants are at particular risk. The microorganism has been isolated from a variety of foods including contaminated infant milk formula powder and milk powder substitute. The study aimed to evaluate the level of microbiological contamination in 47 samples of mozzarella cheese made with cow's milk collected from artisan cheese producers in Southern Italy. Samples were collected from commercial sales points and underwent qualitative and quantitative microbiological analyses to test for the bacterial contaminants most commonly found in milk and cheese products. The 47 samples underwent qualitative and quantitative microbiological tests according to ISO UNI EN standards. Analyses focused on Staphylococcus aures, Salmonella spp., Listeria monocytogenes, Pseudomonas spp., E. coli, Yersinia spp., total coliforms and Cronobacter sakazakii. The ISO/TS 22964:2006 method was used to investigate possible contamination by $C$. sakazakii. Biochemical identification was carried out using an automated system for identification and susceptibility tests. None of the samples examined resulted positive for Salmonella spp. or Listeria spp. Only one sample resulted positive for Staphylococcus aureus. Pseudomonas spp. was isolated in 10 (21\%) of 47 samples. High levels of total coliforms were found in $\mathbf{1 0}$ of 47 samples. Cronobacter spp. (Enterobacter sakazakii) was isolated in one sample.

This is the first study to confirm isolation of C. sakazakii in artisan mozzarella cheese made from cow's milk. The presence of $C$. sakazakii could be related to external contamination during the phases of production or to the use of contaminated milk. Since mozzarella is recommended in the diet of children and adults of all ages, this present study helps define it as a potential vehicle for $C$. sakazakii in subjects at particular risk.

\section{Introduction}

Mozzarella is a typical Italian cheese product made by stretching and kneading the drained curd mass. It is mainly made from cow's milk, but over recent years mozzarella made with buffalo's milk has becoming increasingly popular. There has been an increase in national demand and important commercial channels have also opened up both in Europe and toward third party countries, in particular the USA and Asia. This has led to significant changes being made in the industrial production system. However, traditional artisan production, even though carried out on a local level, still represents an important proportion of the commercialisation of milk and cheese products.

Like all milk products, mozzarella is subject to microbiological contamination that can lead to organoleptic alteration, or even to episodes of food poisoning. Studies have been carried out to determine the qualitative and quantitative levels of microbiological contamination in mozzarella made with cow's milk produced in traditional artisan systems in some parts of southern Italy. Besides the classical contaminants and pathogens, these studies also looked for Cronobacter spp. (Enterobacter sakazakii) that is currently considered an emerging opportunistic pathogen of food origin. This genus was originally described as Enterobacter cloacae, and after 1980 was named Enterobacter sakazakii (Farmer et al., 1980). It has recently been reclassified as a new genus, Cronobacter spp. (Iversen et al., 2007, 2008), consisting of seven species: $C$. sakazakii, $C$. malonaticus, $C$. turicensis, $C$. universalis, $C$. muytjensii, $C$. dublinensis, and $C$. condimenti (Joseph et al muytjensii, dublinensis and genomospecies., 2012). This opportunistic bacterial pathogen is capable of causing disease and even fatalities in newborn infants within the first weeks of life if consumed as part of the diet. Still, not only are premature and immunocompromised newborn infants at particular risk, but also immunocompromised adults, particularly the elderly. Episodes of meningitis, sepsis, and necrotising enterocolitis (NEC) caused by Cronobacter spp. are the most frequent pathologies involved (Healy et $a l ., 2010)$ and they are almost always linked to contaminated milk powder consumption (van Acker et al., 2001).

The microorganism has also been isolated in artificial milk, cereals, fruit and vegetables, meat (Kandhai et al., 2004; Hunter et al., 2008), legumes, herbs and spices, fresh, frozen, cooked and dried food (Chon KwangYoung Song tet al., 2012), drinks and beverages, and water used to prepare food (Friedemann, 2007). C.sakazakii sakazakii has also been isolated in cow's (Liu et al., 2006)
Correspondence: Francesco Casalinuovo, Istituto Zooprofilattico Sperimentale del Mezzogiorno Sezione di Catanzaro, viale Crotone, 88100 Catanzaro, Italy.

Tel. +39.0961.737763 - Fax: +39.0961 .738088 . E-mail: francesco.casalinuovo@cert.izsmportici.it

Key words: Cheese, Cronobacter spp. Enterobacter sakazakii, Milk, Mozzarella.

Conflict of interests: the authors declare no potential conflict of interests.

Received for publication: 26 March 2013.

Revision received: 30 August 2013.

Accepted for publication: 2 September 2013.

This work is licensed under a Creative Commons Attribution 3.0 License (by-nc 3.0).

(C) Copyright F. Casalinuovo et al., 2014

Licensee PAGEPress, Italy

Italian Journal of Food Safety 2014; 3:1526

doi:10.4081/ijfs.2014.1526

and donkey's (Conte and Passantino, 2008) milk. In a recent study by Hochel et al. (2012), Cronobacter spp. was isolated in 53 of 399 samples of commercialised food products and over half of the isolates (53\%) were represented by the sakazakii species. Isolates from cheeses have been reported in various countries (Chavez-Lopez et al., 2006; Morales et al., 2004; Restaino et al., 2006; Aigbekaen and 0shoma, 2010; Adeyemi, 2012; El-Sharoud et al., 2008). In particular, it has been seen that $C$. sakazakii can survive for up to one month in cheese produced in experimental conditions with contaminated milk powder. This causes considerable concern for the microbiological safety of cheeses prepared with or containing milk powder (El-Sharoud et al., 2008). The pathogen is capable of resisting osmotic pressure, high temperatures and drying (Fang et al., 2012). These characteristics explain why it can survive the processes used in the production of infant milk powder and of other similar products (Nazarowec and Farber, 1997; Breeuwer et al., 2003). Bacterial acid resistance at $\mathrm{pH} 3$ (Edelson-Mammel et al., 2006) has also been demonstrated and this explains why the pathogen can survive during transit in the newborn stomach.

\section{Materials and Methods}

This study aimed to evaluate the risk of bacterial pathogenic contamination of mozzarella made with cow's milk. The study examined 47 samples from small traditional cheese producers in a well-defined area of southern Italy. These are characterised by small-scale, artisan 
cheese production methods and a limited marketing area.

The production process uses cow milk either in crude form or heated to approximately $85^{\circ} \mathrm{C}$ for 10-15 seconds. Natural fermented milk whey is added to promote acidification and natural veal rennet is used for coagulation. The curd is then broken up into pieces, kneaded and stretched so as to make samples of mozzarella cheese of different weight and shape.

The product is then placed in brine, and packaged and sold in its original liquid or whey (water, salt and serum diluted acid). If stored in its original whey and kept in a refrigerator at a constant temperature, the product maintains its natural characteristics for 3-4 days.

The study was carried out over a 6-month period between November 2012 and April 2013. One sample from each producer was collected together with its original whey directly from the retail sales point. Samples underwent qualitative and quantitative microbiological tests according to ISO regulations for the following parameters: Staphylococcus aures (UNI EN ISO 6888-1:2004), Salmonella spp. (UNI EN ISO 6579:2008), Listeria monocytogenes (UNI EN ISO 11290-1:2005), Pseudomonas spp. (ISO/TS 1059:2009), E. coli (ISO 16649-2:2001), Yersinia spp. (UNI EN ISO 10273:2005), total coliforms (ISO 4832:2006) and Cronobacter sakazakii. Samples were examined for $C$. sakazakii using the ISO/TS 22964:2006 Milk and milk products-Detection of Enterobacter sakazakii isolation method involving the following phases: i) pre-enrichment in buffered peptone water and incubated at $37 \pm 1^{\circ} \mathrm{C}$ for 16 $20 \mathrm{~h}$; ii) enrichment in liquid medium with 0.1 $\mathrm{mL}$ inoculum in modified lauryl sulfate tryptose (mLST) broth/vancomycin medium and incubated at $44^{\circ} \mathrm{C}$ for $24 \mathrm{~h}$; iii) addition in solid medium of selective Cronobacter sakazakii (ESIA) chromogene at $44^{\circ} \mathrm{C}$ for $24 \mathrm{~h}$; iv), typical colonies were isolated and purifed on Trypticase Soy Agar (TSA) medium. To conclude, isolated strains are identified through single biochemical tests or through an automated system. In the present study the automated system has been used Vitek® (BioMérieux, Marcy l'Etoile, France).

\section{Results}

The study was carried out in the context of the typical problems and limitations of artisan food production systems. However, in spite of this, results from microbiological tests showed a generally acceptable level of health and hygiene for this type of cheese production. Table 1 shows the general results of the tests carried out on the 47 samples of mozzarella cheese, one sample from each of the artisan cheese producers taking part in the study.
Cronobacter sakazakii was isolated in only one mozzarella sample (2.1\%), in association with other contaminants such as Citrobacter freundii and Aeromonas hydrophila. None of the samples tested positive for Salmonella spp. or Listeria monocytogenes. Only one sample tested positive for Staphylococcus aureus $\left(>10^{5}\right.$ $\mathrm{ufc} / \mathrm{g}$ ) in the absence of enterotoxins. However, samples frequently tested positive for other pathogens: Pseudomonas spp (21\%, represented by the species $P$. aeruginosa, $P$. fluorescens and $P$. putida), Citrobacter spp (21\%, $C$. braakii and $C$. freundii), Enterobacter spp $(17 \%, E$. cloacae, E. aerogenes and E. amnigenus) and Enterococcus spp (36\%, E. faecium, E. faecalis, E. casseliflavus and E. gallinarum). Samples also tested positive for Klebsiella spp, Serratia spp and Aeromonas spp.

Total coliform values of over $10^{5} \mathrm{ufc} / \mathrm{g}$ were found in $29(61.7 \%)$ of 47 samples analyzed while 13 of 47 samples (27\%) had values of $E$. coli over $10^{3} \mathrm{ufc} / \mathrm{g}$. One sample of 47 was contaminated by $C$. sakazakii with $6.2 \mathrm{mg} / 100 \mathrm{~g}$ of furosin (-N-2-furoylmethyl--lysine), a molecule commonly used as an indicator to evaluate the effects of heat treatments applied to milk or the addition of milk powder or UHT to crude or pasteurised milk. The European Union maximum limit for mozzarella has been set at 10 $\mathrm{mg}$ in $100 \mathrm{~g}$ of protein substance (Regulation 2527/98/CE).

Antibiotic susceptibility was tested using a Kirby-Bauer agar disc diffusion method (Bauer et al., 1966). The strain isolated was sensitive to streptomycin, tetracycline, kanamycin, ofloxacyn and cephalothin, and was resistant to amoxicillin, vancomycin, rifampicin, ampicillin and lincomycin.

\section{Discussion}

Isolation of $C$. sakazakii in fresh mozzarella cheese produced in an artisan system sheds more light on food contamination by the bacterium from an epidemiological perspective. Indeed, its isolation shows to what extent consumers are exposed to the risk of diseases supported by the microorganism. Mozzarella is light and easy to digest, and because of this, is often recommended in the diet of subjects of all ages. It is particularly recommended for children, adults and bedriddens affected by a whole range of pathologies. Thus, tese subjects could be even more exposed to $C$. sakazakii infection if they eat contaminated mozzarella.

The mozzarella sample that was found to be contaminated with $C$. sakazakii had been produced with raw milk, collected and analyzed in the summer of 2012. Although this is a product that is eaten throughout the year, the biggest consumer demand is concentrated above all in the summer months because of the seasonal preference for fresh, light and easily digested foods. In these cases, mozzarella producers must, therefore, respond to the notable increase in demand precisely at that time of year when milk production is more seriously compromised by a series of negative factors, such as climate and seasonal food preferences (Mariani et al., 1998; Summer et al., 1998).

In the present study, isolation of $C$. sakazakii in a sample of mozzarella has also made it necessary to evaluate the origin of contamination.

The cheese factory involved was an authorised producer who had been approved according to EU regulations in force.

The producer declared that only fresh locally produced cow's milk is used. However, there have been repeated reports of the fraudulent addition of milk powder for zootechnical use reconstituted in the production of cheeses. This is an illegal practice carried out for economic reasons. But it can be proven through laboratory tests that can show the qualitative and quantitative modifications of some indicators, such as furosin, in commercialised milkcheese products (Resmini and Pellegrino, 2003). The mozzarella sample that tested positive for $C$. sakazakii showed furosin levels within normal values $(6.2 \mathrm{mg} / 100 \mathrm{~g})$. This, therefore, excluded the possibility of contamination through the use of milk powder. Other possible origins of contamination by $C$. sakazakii were hypothesised to lie in the production process and the milk used.

Mozzarella production requires a large quantity of water, both during the actual production phase and in maintaining the natural conditions of the product for sale, by immersion in a mixture of water and whey.

Therefore, the use of water contaminated with $C$. sakazakii could be a probable hypothesis (Friedemann, 2007), also given the ability of some strains to stick to work surfaces made of silicon, latex, polycarbonates and steel (Iversen et al., 2004).

The temperatures used during the production process of mozzarella from not heat treated milk are not usually able to affect any $\mathrm{C}$. sakazakii contamination that may be present in the raw material, from where could also have origin the contamination of the final product.

In general, the qualitative and quantitative microbiological tests conducted on the $47 \mathrm{moz}$ zarella samples showed microbial contamination as an expression of health and hygiene conditions (total coliforms, E. coli) in approximately $70 \%$ of the samples already at the beginning of the sales phase. Therefore, this seems to confirm that the origin of the contamination by $C$. sakazakii lies in the contamination of the milk destined for transformation or to external contamination during the production phases. 
Table 1. Results of the microbiological tests performed on 47 samples of mozzarella produced and marketed by artisan dairies in Southern Italy.

\begin{tabular}{lc} 
Microbiological parameters & Number of positive samples (\%) \\
Salmonella spp. & 0 \\
Cronobacter sakazakii & $1(2.1)$ \\
\hline Listeria monocytogenes & 0 \\
Yersinia enterocolitica & 0 \\
\hline E. coli & $10(21)$ \\
Staphylococcus aureus & $1(2.1)$ \\
Pseudomonas spp. & $10(21)$ \\
Total coliforms & $29(61.7)$ \\
\hline
\end{tabular}

\section{Conclusions}

All health and food agencies around the world agree that $C$. sakazakii represents a serious threat to subjects at risk (FDA, 2002; FAO/WHO, 2008). The same European Union regulation concerning food safety, and in particular Regulations (CE) 2073/2005 as amended by Regulation (CE) 365/2010, expressly require tests be carried out for Enterobacter sakazakii on infant milk powder. This has so far found contamination by this bacterium in 13 countries from among those where targeted investigations have been carried out. In order to evaluate the risk $C$. sakazakii presents for food health and safety, it is important to identify the food products that can act as a vehicle for this microorganism. Results of our research confirm that mozzarella cheese produced in artisan systems can potentially be subject to contamination by $C$. sakazakii.

\section{References}

Adeyemi P0, 2012. The incidence of Enterobacter sakazakii (Cronobacter spp.) in unripened soft cheese ("wara") sold in Odeda local Government. Department of Food Science and Technology, Federal University of Agriculture ed., Abeokuta, Nigeria.

Aigbekaen BO, Oshoma CE, 2010. Isolation of Enterobacter sakazakii from powdered foods locally consumed in Nigeria. Pak J Nutr 9:659-63.

Bauer AW, Kirby WM, Sherris JC, Turck M, 1966. Antibiotic susceptibility testing by a standardized single disk method. Am J Clin Pathol 45:493-6.

Breeuwer P, Lardeau A, Peterz M, Joosten HM, 2003. Desiccation and heat tolerance of Enterobacter sakazakii. J Appl Microbiol 95:967-73.

Chavez-Lopez C, De Angelis M, Martuscelli A, Serio, A. Paparella, G. Suzzi, 2006.
Characterization of the Enterobacteriaceae isolated from an artisanal Italian ewe's cheese (pecorino abruzzese). J Appl Microbiol 101:353-60.

Chon JW, Young K, Young K, Kim SY, Ji-Yeon Hyeon, Hyeon JY, Kun-Ho SeoSeo KH, 2012. Ji-Yeon Hyeon,Kun-HIsolation and characterization of Cronobacter from desiccated foods in Korea. J Food Sci 77:3548.

Conte F, Passantino A, 2008. Isolation of Sicily: case report, safety and legal issues. Travel Med Infect Dis 6:250-2.

Edelson-Mammel S, Porteous MK, Buchanan RL, 2006. Acid resistance of twelve strains of Enterobacter sakazakii, and the impact of habituating the cells to an acidic environment. J Food Sci 71:201-7.

El-Sharoud WM, El-Din MZ, Ziada DM, Ahmed SF, Klena JD, 2008. Surveillance and genotyping of Enterobacter sakazakii suggest its potential transmission from milk powder into imitation recombined soft cheese. J Appl Microbiol 105:559-66.

Fang T, Gurtler JB, Huang L, 2012. Growth kinetics and model comparison of Cronobacter sakazakii in reconstituted powdered infant formula. J Food Sci 77:247-55.

FAO/WHO, 2008. Enterobacter sakazakii (Cronobacter spp.) in powdered follow-up formulae. FAO ed., Rome, Italy.

Farmer JJ, Asbury MA, Hickman FW, Brenner Don J, 1980. Enterobacter sakazakii: a new species of "Enterobacteriaceae" isolated from clinical specimens. Int $\mathrm{J}$ Syst Evol Micr 30:569-84.

FDA, 2002. Freedom of information annual report. FDA ed., Rockville, MD, USA.

Friedemann M, 2007. Enterobacter sakazakii in food and beverages (other than infant formula and milk powder). Int $\mathrm{J}$ Food Microbiol 116:1-10.

Healy B, Cooney S, O'Brien S, Iverven C, Whyte P, Nally J, Callanan JJ, Fanning S, 2010. Cronobacter (Enterobacter sakazakii): an opportunistic foodborne pathogen. Foodborne Pathog Dis 7:339-50. Enterobacter sakazakii from ass' milk in
Hochel I, Rikov H, Krsn L, Demnerov K, 2012. Occurrence of Cronobacter spp. in retail foods. J Appl Microbiol 112:1257-65.

Hunter CJ, Petrosyan M, Ford HR, Prasadarao NV, 2008. Enterobacter sakazakii: an emerging pathogen in infants and neonates. Surg Infect (Larchmt) 9:533-9.

Iversen C, Lane M, Forsythe SJ, 2004. The growth profile, thermotolerance and biofilm formation of Enterobacter sakazakii grown in infant formula milk. Lett Appl Microbiol 38:378-82.

Iversen C, Lehner A, Mullane N, Bidlas E, Cleenwerck I, Marugg J, Fanning S, Stephan R, Joosten H, 2007. The taxonomy of Enterobacter sakazakii: proposal of a new genus Cronobacter gen. nov. and descriptions of Cronobacter sakazakii comb. nov. Cronobacter sakazakii subsp. sakazakii, comb. nov., Cronobacter sakazakii subsp. malonaticus subsp. nov., Cronobacter turicensis sp. nov., Cronobacte muytjensii sp. nov., Cronobacter dublinensis sp. nov. and Cronobacter genomospecies. BMC Evol Biol 7:64.

Iversen C, Mullane N, McCardell B, Tall BD, Lehner A, Fanning S, Stephan R, Joosten H, 2008.

Cronobacter gen. nov., a new genus to accommodate the biogroups of Enterobacter sakazakii, and proposal of Cronobacter sakazakii gen. nov. comb. nov., C. malonaticus sp. nov., C. turicensis sp. nov., C. muytjensii sp. nov., C. dublinensis sp. nov., Cronobacter genomospecies 1 , and of three subspecies, C. dublinensis sp. nov. subsp. dublinensis subsp. nov., C. dublinensis sp. nov. subsp. lausannensis subsp. nov., and C. dublinensis sp. nov. subsp. lactaridi subsp. nov.". Int J Syst Evol Micr 58:1442-7.

Joseph S, Sonbol H, Hariri S, Desai P, McClelland M, Forsythe SJ, 2012. Diversity of the Cronobacter genus as revealed by multilocus sequence typing. J Clin Microbiol 50:3031-9.

Kandhai MC, Reij MW, Gorris LG, GuillaumeGentil 0, van Schothorst M, 2004. Occurrence of Enterobacter sakazakii in food production environments and households. Lancet 363:39-40.

Liu Y, Gao Q, Zhang X, Hou J, Yang J, Huang X, 2006. PCR and oligonucleotide array for detection of Enterobacter sakazakii in infant formula. Mol Cell Probe 20:11-7.

Mariani P, Summer A, Formaggini P, Beltrami A, Sandri S, 1998. [Andamento mensile delle principali caratteristiche di coagulazione del latte di singoli allevamenti di vacche da latte di razza frisona con particolare riguardo alla velocità di formazione del coagulo]. [Article in Italian]. Available from: http://www.ismea.it/flex/AppData/ 
Redational/Normative/pubnaz/200007 10000100356.pdf

Morales P, Feliu I, Fernandez-Garcia E, Nunez $\mathrm{M}, 2004$. Volatile compounds produced in cheese by Enterobacteriaceae strains of dairy origin. J Food Protect 67:567-73.

Nazarowec MW, Farber JM, 1997. Thermal resistance of Enterobacter sakazakii in reconstituted dried-infant formula. Lett Appl Microbiol 24:9-13.

Resmini P, Pellegrino L, 2003. Furosine and other heat-treatment indicators for detecting fraud in milk and milk products Italian. J Food Sci 15:473-84.

Restaino L, Frampton EW, Lionberg WC, Becker RJ, 2006. A chromogenic plating medium for the isolation and identification of Enterobacter sakazakii from foods, food ingredients, and environmental sources. J Food Protect 69:315-22.

Summer A, Martuzzi F, Vecchia P, Mariani P, 1998. [Variazioni stagionali dell'indice di caseina in latti di massa di singoli allevamenti bovini di razza frisona]. [Article in Italian]. Available from: http://www. ismea.it/flex/AppData/Redationa//Normati ve/pubnaz/200007 10000100439.pdf

van Acker J, de Smet F, Muyldermans G, Bougatef A, Naessens A, Lauwers S, 2001. Outbreak of necrotizing Enterocolitis associated with Enterobacter sakazakii in powdered milk formula. J Clin Microbiol 39:293-7. 